\title{
AAN position statement:
}

\section{The COVID-19 pandemic and the ethical duties of the neurologist}

Michael A. Rubin, MD, MA, Richard J. Bonnie, LLB, Leon Epstein, MD, Claude Hemphill, MD, MAS, Matthew Kirschen, MD, PhD, Ariane Lewis, MD, and Jose I. Suarez, MD, on behalf of the Ethics, Law, and Humanities Committee, a joint committee of the American Academy of Neurology, American Neurological Association, and Child Neurology Society; in collaboration with the Neurocritical Care Society Ethics Committee

Neurology ${ }^{\circledR}$ 2020;95:167-172. doi:10.1212/WNL.0000000000009744

\section{Abstract}

Patients, clinicians, and hospitals have undergone monumental changes during the coronavirus disease 2019 (COVID-19) pandemic. This crisis has forced us to consider the obligations that we neurologists have to our individual patients as well as the greater community. By returning to our fundamental understanding of these duties, we can ensure that we are providing the most ethically appropriate contingency and crisis care possible. We recommend specific adaptations to both the inpatient and outpatient settings, as well as changes to medical and trainee education. Furthermore, we explore the daunting but potentially necessary implementation of scare resource allocation protocols. As the pandemic evolves, we will need to adapt continuously to these rapidly changing circumstances and consider both national and regional standards and variation.

As the coronavirus disease 2019 (COVID-19) pandemic expands through the United States, every aspect of health care has undergone substantial change, including home offices and kitchen tables becoming the nexus of telehealth for remote patient care as well as virtual meeting places with colleagues. Inpatient admissions are restricted to those with medical necessity. Health care teams are repurposing hospital spaces as their missions have changed from providing the highest quality of care for all patients to caring predominately for the most ill. Regional variability is substantial, with some hospitals overloaded with activity while others appear eerily quiet as they stockpile resources and isolate staff in preparation for the surge to come. The universal goal is to avoid the daunting prospect of scarce resource allocation, where the demand exceeds the supply of critical care beds, ventilators, and the physicians, nurses, and therapists to manage them.

Whereas the similarities are greater than the differences, neurology patients warrant their own specific considerations. This position paper is intended to offer an overview and guidance on the ethical dimensions of care of patients with neurologic conditions during the COVID-19 pandemic. It is offered for use by both leaders and individual clinicians adapting to the crisis. Furthermore, it is intended to assist in the development of regional scarce resource allocation policies and to assist triage committees in making the difficult decisions that they may confront.

\section{Correspondence}

Dr. Rubin

Michael.Rubin@

utsouthwestern.edu
MORE ONLINE

\section{COVID-19 Resources}

For the latest articles, invited commentaries, and blogs from physicians around the world NPub.org/COVID19

From the Department of Neurology \& Neurotherapeutics and Neurological Surgery (M.A.R.), University of Texas Southwestern Medical Center, Dallas; Schools of Law, Medicine, and Public Policy (R.J.B.), University of Virginia, Charlottesville; Department of Pediatrics (L.E.), Northwestern University Feinberg School of Medicine, Chicago, IL; Departments of Neurology and Neurological Surgery (C.H.), University of California, San Francisco; Departments of Anesthesiology, Critical Care Medicine, Pediatrics and Neurology (M.K.), University of Pennsylvania Perelman School of Medicine, Philadelphia; Departments of Neurology and Neurosurgery (A.L.), New York University Langone Medical Center, New York; and Departments of Anesthesiology and Critical Care Medicine, Neurology, and Neurosurgery (J.I.S.), The Johns Hopkins University School of Medicine, Baltimore, MD.

Go to Neurology.org/N for full disclosures. Funding information and disclosures deemed relevant by the authors, if any, are provided at the end of the article.

This statement was approved by the Ethics, Law, and Humanities Committee, a joint committee of the American Academy of Neurology, American Neurological Association, and Child Neurology Society, on April 13, 2020

This statement was approved by the American Academy of Neurology on April 20, 2020; American Neurological Association on April 24, 2020; Child Neurology Society on April 20, 2020; and Neurocritical Care Society on April 21, 2020 


\section{Glossary}

CDC $=$ Centers for Disease Control and Prevention; COVID-19 = coronavirus disease 2019; ICU = intensive care unit.

\section{Balancing the duties of the physician}

Deferring patient interventions and selectively allocating medical resources is distasteful for physicians, whose primary obligation is to advocate for the well-being of their individual patients. This duty generally takes precedence over other priorities; however, we also have an obligation to support public welfare, which usually manifests in such ways as reporting communicable disease and fostering stewardship in health care expenditures. Clinicians in the United States may be particularly uncomfortable when facing the prospect of withholding beneficial care because we are so accustomed to providing expensive evaluations and interventions that may be disproportionate to their benefit. In a public health care crisis, the goals of ensuring public welfare and individual patient advocacy will come into conflict.

When the need for life-sustaining medical resources exceeds the supply, the obligation to support public welfare and specifically to save the most lives possible takes on a greater priority and becomes the primary ethical goal for medical and public health professionals. In such circumstances, the American Medical Association Code of Ethics supports policies for allocating limited resources even if they may inhibit our ability to benefit our individual patients. ${ }^{1}$ As supported by the Centers for Disease Control and Prevention (CDC) Pandemic Ethical Guidelines, resource allocation/triage criteria should be based on need, prospect of benefit, best medical evidence, and the balance of personal freedoms with community interest. ${ }^{2}$ Such allocation policies should be objective, flexible, applied consistently, developed with broad public input, and implemented on an institutional rather than individual level. As discussed in a recent article in the Hastings Center Report, the medical and ethics communities have reached a consensus that the goal of allocation policies during a public health crisis should be a fair distribution of resources, whether they be material or human capital, with emphasis placed on the need to maximize the survival of the largest number of patients. ${ }^{3}$

Despite this consensus, disturbing trends in socioeconomic and racial disparities have emerged regarding the effect of COVID-19, illustrating how underlying challenges in our health care system are exacerbated in a crisis. More specifically, patients in African American and Hispanic communities with a higher prevalence of comorbid diseases who also may be economically disadvantaged and living in more crowded housing with reduced opportunities for social distancing are showing higher rates of COVID-19. ${ }^{4 .}$ Likewise, there is some concern about these disparities being passed forward into scare resource allocation protocols.
Whereas national guidance often focuses on institutional policies, we must also be aware that each of us has an ethical obligation to evaluate how this crisis is affecting our efforts to balance our duties as neurologists. For now, we cannot approach individual patient care issues in the same way in which we are accustomed. We must consider how decisions affect not only our individual patients, but also the other patients in our institution, those with COVID-19, and the greater community. Without question, our colleagues in advanced practice, nursing, social work, and allied health professions will be similarly affected by this crisis and will also have to adapt rapidly. In the remainder of this article, we review various areas of our practice and how they can and are being adapted to balance our conflicting priorities.

\section{Telehealth, chronic neurologic disease, and goals of care}

Appointments should ordinarily be held via telehealth, an evidence-based practice that has already become part of neurologic patient care. ${ }^{5}$ This allows the ability to continue to care for our patients during the pandemic while balancing the need to reduce exposure events and prevent further spread of COVID-19. This leads to challenges to physician-patient communication, such as loss of nonverbal communication cues and risk of losing some of the warmth of an in-person interaction. Telehealth can be particularly problematic for neurologists, as it limits the physical examination, with more emphasis on observation than our traditional hands-on approach. Behavioral health evaluations and family dynamics can likewise be more difficult to discern with such technology. Our routine diagnostic EEGs, EMGs, and sleep studies will likely need to be delayed, and some brain imaging might be safely postponed. Clinicians should discuss with their patients the risks of delaying diagnostic studies and the limitations of telehealth. Each clinician should decide, in concert with his or her patient, if an in-person evaluation warrants the risk of an encounter. Some patients may still gravitate toward in-person visits, but others may find telehealth interactions expeditious and prefer them. The risk-benefit analysis will change as the stage of the pandemic evolves.

Discussing quality of life and goals of care is already an integral part of managing chronic neurologic diseases, but neurologists now also need to consider and discuss with their patients the possible consequences of interacting with an overstressed health care system. Those who do not have COVID-19 may have to contend with substantial delays in hospital services or need to defer less urgent care. Neurologists should counsel their patients about how their relative risk of hospitalization and death due to COVID-19 may be affected by their 
neurologic condition and its management. Entering a hospital or outpatient facility may impose a greater risk of infection than normal, even if appropriate precautions are taken. For example, patients on corticosteroids or chronic immunomodulation may be more susceptible to acquiring COVID-19. Even if desired services are available, neurologists and their patients ought to consider whether their care plans can be delayed safely in order to mitigate risk.

In the event of hospitals having to triage limited resources, patients with neurologic disease contributing to a low likelihood of survival from respiratory illness may not be offered certain elements of care, such as ventilators and intensive care unit (ICU) beds. It would be reasonable for patients with advanced disease and their surrogate decision-makers to discuss with their neurologist how reduced resources may affect their care if they were to become seriously ill. This will require the neurologist to be aware of the burden of disease in the local community and how health care leaders plan on coping with a surge. Essential to good care planning is taking every step possible to ensure that patients with capacity have an opportunity to choose what treatments they will receive from those that will be available and are medically appropriate. It is also important to encourage patients to consider their preferences if they require hospital and ICU support upon becoming ill with COVID-19. Proactive planning and advance directives should be a standard part of the care provided by neurologists and primary care clinicians, a fact made even more pressing during the COVID-19 pandemic. Now is the time to complete advance care planning documents for those who have not already done so, including preferences for do not attempt resuscitation status. Advance directives may require special accommodations if they require an in-person witness signature. We must assure patients with chronic illness that diminished resources in this health care crisis will not restrict their access to comfort and palliative care.

\section{Competing clinical assignments and practicing out of our usual scope}

Neurologists and subspecialist neurologists need to consider how to manage competing clinical assignments during the COVID-19 pandemic. The medical needs of neurology patients will continue during the pandemic; however, inpatient-focused neurologists may be called upon to help with non-neurology patients. Outpatient-focused neurologists may also be asked to help cover inpatient service lines if their colleagues become ill or as patient volumes increase. Acute admissions for status epilepticus, Guillain-Barré syndrome, stroke, and encephalopathy will still occur while admissions for respiratory disease increase dramatically.

During the pandemic, when internal medicine and family practice physicians are overwhelmed with respiratory illness, the neurohospitalist with an internal medicine background may be called upon to help manage internal medicine patients admitted to a general medical service, or even to help manage patients with COVID-19 who do not require ICU admission. Outpatient focused neurologists, also with internal medicine experience, may be asked to manage a general medical service. As intensivists, critical care neurologists are among the limited group of physicians who have experience in managing ventilators for patients with respiratory failure. Consequently, they may be asked to manage critically ill patients admitted for COVID-19-associated respiratory failure. This raises 2 questions. First, how should these clinicians balance their obligation to manage their own patient population while supporting the remainder of the hospital community? Second, is it acceptable to ask them to manage issues that are not within their primary area of training?

Whereas the decreased case load caused by the delay of nonurgent procedures may ameliorate some of the burden of conflicts of duty, these problems are still highly likely to arise. Neurologists still have an obligation to manage the patients for whom they were trained but, as time permits, they should help manage the surge of respiratory failure. Divisions can split the responsibilities, with some members managing the inpatient neurology service lines, and the remainder contributing to COVID-19 patient care. If this is not feasible based on available physician resources, then physician time should be prioritized to caring for those with the most urgent need first. Whereas becoming a specialist does require taking responsibility for a focused patient population, it does not obviate the duty we have as physicians to support the greater community. Regarding the appropriateness of managing patients outside of one's primary skill set, if limited expertise is available and the neurologist has some qualification beyond that which is otherwise available, then the urgency of crisis makes it ethically permissible to offer the care of which he or she is capable. Government-declared states of emergency may provide liability protection in these circumstances, and hospitals should not ask their physicians to perform duties outside their expertise without associated legal protection.

\section{Tertiary-care referral centers and specialist consultation}

Individual neurologists and operational leaders at referral centers should consider whether the support they provide the greater community needs to be adjusted during a pandemic health emergency. Many hospitals depend on such support and refer patients to tertiary centers for specialty care. Tertiary centers, however, may be redirecting their neurology resources to confront the pandemic patient surge. In the spirit of fulfilling our commitment to the greater community, we encourage referral centers to continue to provide urgent and emergent neurologic care. Community hospitals may be unable to compensate for the loss of a referral center as they adapt to the pandemic. For example, comprehensive stroke centers should continue to accept patient transfer for acute stroke interventions. Likewise, if a referral center usually 
provides neurology specialist consultations, it should continue to do so, although it may need to convert them to telehealth appointments. Tertiary care centers should not have any obligation to offer services that they are not currently able to offer for their own internal patient base due to the need to mitigate the risk of propagating infection or adapting to a patient surge. The catchment area of referral centers may be expanded if neighboring regions can no longer rely on their own academic centers that become overwhelmed by a patient surge.

\section{Educational and teaching obligations}

Education of the next generation of neurologists must continue during this pandemic. Neurology education for trainees at all levels is grounded in the neurologic examination and subsequent cognitive exercises of lesion localization and differential diagnosis. To replace these bedside teaching opportunities, we should increase didactics via remote access learning and make a conscious effort to include video demonstrations of examination findings and facilitate interactive discussions.

At some institutions, neurology residents or fellows may be needed to care for patients with COVID-19 on either the neurology or general medicine wards. Some trainees (and some attendings) feel vulnerable about being exposed to the disease or anxious about treating patients with COVID-19, recognizing that their decisions also have potential consequences for their families and friends. Trainees might also be concerned that having fewer procedures will preclude them from meeting credentialing requirements and that their inability to maintain their skill set will negatively affect them when they return to traditional clinical care. ${ }^{6}$

Caring for patients with COVID-19 can provide rich educational opportunities but needs to be balanced with the best care for the patient and the well-being of the trainee. Guidance for this balance can be drawn from the core tenets of the Association of American Medical Colleges' Compact Between Resident Physicians and Their Teachers: Excellence in Medical Education, Highest Quality Patient Care and Safety, and Respect for Residents' Well-Being. ${ }^{7}$ Trainees who do not feel compelled to put their own safety at risk should never be forced to do so, but those who choose to do so should be provided all necessary knowledge and skills to provide care as safely and effectively as possible. We should use this crisis as an opportunity to provide education and role modeling about clinical ethics topics like autonomy and distributive justice as well as reinforce the importance of skills like professionalism and humanism in neurology.

\section{Scarce resource allocation protocols}

Triage is not novel for the medical profession, but rationing and abrupt change to this extent are likely beyond the experience of many current neurologists. As Emanuel et al. ${ }^{8}$ noted recently, rationing is already upon us in the COVID-19 pandemic. Surgical and N95 masks are in short supply and testing for presence of disease is limited. Consequently, someone has to decide who gets the masks and who gets tested, and who does not. ICU beds, ventilators, and the staff who manage them are in limited supply, with calls for equipment and personnel coming from areas with significant shortfalls. ${ }^{9}$ The potential need to remove a ventilator from a patient who is not improving in order to benefit another patient who is more likely to survive will lead to extensive moral distress. Despite these monumental challenges, failing to modify practice would reduce our ability to control how many lives we can save with the equipment and staff that we have. We must face the problem of resource allocation head on and transparently, in order to assure professional solidarity and preserve public trust.

Scarce resource allocation protocols, also known as triage protocols, are generally activated once the hospitals have surged past any contingency plans and are working in crisis mode. Often, they require a declared state of emergency or the governor activating the triage plan. This will surely be the most challenging aspect of patient care during this pandemic public health emergency. Reserve supplies and creative uses of ventilators and related staff may prevent the need to invoke the triage protocols; however, if contingency plans are not sufficient, a plan should already be in place. The complexity and sensitivity of creating and implementing these plans will require significant institutional investment in expertise and deliberation. The extended length of time that many patients with COVID-19 will require ventilatory support complicates the situation, as a ventilator in use may be out of the availability pool for weeks. Moral distress will accompany implementation of such plans, as rationing decisions always include comparisons among multiple patients who might all receive some benefit. ${ }^{10}$ Accepting that difficult truth is a prerequisite for being able to create an allocation protocol that is fair and equitable, as well as effective in maximizing lives saved.

Such triage protocols will require specialized teams composed of intensivists, clinical ethicists, and nursing representatives not directly involved in the care of the critically ill patients to ensure transparency and consistency and mitigate the emotional effect of these decisions on clinicians and patients. Allocation protocols most often use a multitiered schema that changes depending on the pressure of the situation. There is an initial patient assessment, with regular reevaluations to determine if those currently using limited resources are benefiting less than other patients with a need for the same resource. Most existing protocols focus on the primary intent to maximize the number of lives saved, with some including other modifiers in their algorithm. Furthermore, there is universal ethical consensus that decisions should not be based on race, sex, ethnicity, socioeconomics, or perceived social worth. $^{11,12}$ Each hospital (and ideally each region or state) should develop a system consistent with its local needs and practice culture, with broad input from clinicians, ethicists, 
lawyers, and patients. Community and the lay perspective cannot be underestimated, as our ability to maintain trust in the health care system requires the public acceptance of implementing such a significant, albeit time-limited, change in medical practice.

Allocation protocols need to consider mortality predictors not only of patients with COVID-19 but also patients with other diseases that have led to the need for mechanical ventilation. Patients who have influenza, traumatic injuries, stroke, and heart failure will still present to the emergency department in need of mechanical ventilation, even if they have not contracted COVID-19. Consequently, allocation protocols cannot be designed just to risk-stratify patients with COVID-19. In order to create a manageable rubric, protocols depend on objective mortality prediction scales, such as the modified Sequential Organ Failure Assessment. Regarding neurologic disease mortality considerations, we recommend using scales that are currently used as prognostic instruments, such as the CPC scale for hypoxicischemic brain injury, the Glasgow Outcome Scale, the Hunt-Hess scale, or World Federal of Neurosurgery Aneurysm Severity Score for aneurysmal subarachnoid hemorrhage; the IMPACT (International Mission for Prognosis and Analysis of Clinical Trials in TBI) score for traumatic brain injury; the NIH Stroke Scale for ischemic stroke; and the Intracerebral Hemorrhage Score for hemorrhagic stroke. Whereas these prognostic scales have their limitations and were not designed for use as scarce resource allocation protocols, they have been studied extensively, and their use will decrease arbitrary judgments. Because the threshold for mortality and outcome will differ for each scarce resource allocation protocol, we will not recommend specific thresholds for each of these scales. The importance of considering neurology-specific diseases and prognostic scales specific to each condition strongly supports the need to consult a neurologist while developing scare resource allocation protocols.

Protocols vary in some important-and sometimes controversial-respects. Whereas some protocols use exclusion criteria for patients with substantial preexisting conditions, others include baseline comorbidities and conditions as part of a point system. Some protocols consider life cycle stages, including the effect of comorbid medical conditions on the likelihood of completing a full life cycle. Prioritization of health care workers varies among different state and regional protocols, justified by the need to return scarce health care workers back to duty. However, a desire to return health care workers to the front lines may be offset by concerns about eroding public trust in the fairness of the triage process. Quality of life assessments are especially controversial and should not be used, with concern that disabilities will be used as a basis for limiting access to essential resources. The US Department of Health and Human Services Office for Civil Rights released a bulletin on March 28, 2020, expressing concern about protocols discriminating against patients with preexisting conditions, stating that "persons with disabilities should not be denied medical care on the basis of stereotypes, assessments of quality of life, or judgments about a person's relative 'worth' based on the presence or absence of disabilities or age." 13

Concerns for disability discrimination are of particular interest to neurologists, as patients with neurologic disease may survive in a clinical state with limited consciousness or unclear chance of return to a functional state. If triage protocols are based solely on mortality, patients with advanced dementia, minimally conscious state, or persistent vegetative state (unresponsive wakefulness) could still be prioritized for scarce resources at the same level as a patient without these major comorbidities. As neurologists, we are specialist medical experts and thus important stakeholders in the dialogue of whether prioritizing cognitive functional outcome is a valid consideration in addition to patient survival. Whereas preexisting functional status should be considered in a scare resource allocation context, this is contingent on understanding the limitations of our ability to accurately assess the patient's likelihood of recovering consciousness. Therefore, including chronic limited consciousness as a criterion should only be done in extreme situations. We are especially sensitive to concerns about disability rights, and we do not support protocols that would exclude patients because of a spinal cord injury leading to paralysis, a stroke inhibiting movement or language, or a neuromuscular or movement disorder that may limit level of activity. These patients may have a different quality of life, but they can adapt to a different existence.

\section{Further discussions}

Neurologists have responded to the call to battle, as have other physicians, advanced practice providers, nurses, and allied health professionals. For many of us, "pandemic" has been a word of almost historical curiosity, but the COVID19 pandemic will without a doubt be one of the most challenging times of our careers. We must adapt our daily practice and consider how we can care for our most ill neurology patients while contributing to the care of all patients with COVID-19. We must consider the needs of the community and the role we are obligated to play during the crisis. For patients with neurologic disease severe enough to warrant hospitalization, we should endeavor to maintain the customary standard of care for them during the pandemic. Furthermore, we must be acutely aware of how living with the unrelenting stress of the pandemic may affect the care we deliver.

As illness invades our workplace and personal lives, we can ensure that we are making the most ethically appropriate decisions by standing by our core principles-advocating for the wellness of our patients while also fulfilling our obligations to the rest of society. If the situation 
necessitates difficult decisions, we need to be fair, objective, and transparent, and adamantly preserve our professional integrity. We owe it to our patients and families, as well as ourselves, to maintain our own health and wellness. We hope that this position statement provides a helpful framework for neurology teams as they navigate the pandemic, and we encourage our society members and the public to discuss these important issues (in the medical literature and other professional forums) and support one another as we collectively adapt our practices in this challenging environment.

\section{Acknowledgment}

The authors thank the members of the Ethics, Law, and Humanities Committee (a joint committee of the American Academy of Neurology, American Neurological Association, and Child Neurology Society) who contributed to this manuscript by reviewing and offering suggestions, including Barney J. Stern, MD (Johns Hopkins University, Baltimore, MD); Benjamin Tolchin, MD (Yale University, New Haven, CT); Salvador CruzFlores, MD (Texas Tech University, Lubbock); Sok Lee, MD (University of Pennsylvania, Philadelphia); Robin Conwit, MD, FAAN (NIH, Bethesda, MD); Katharina Busl, MD (University of Florida, Gainesville); William Graf, MD (University of Connecticut, Hartford); and Lynne Taylor, MD (University of Washington, Seattle); and contributing members of the Neurocritical Care Society's Neurocritical Care Ethics Committee who contributed to this manuscript by reviewing and offering suggestions, including Michelle Schober, MD (University of Utah, Salt Lake City); Michael Schneck, MD (Loyola University, Chicago, IL); Claire Creutzfeldt, MD (University of Washington, Seattle); and Richard Choi, MD (Christiana Care Health, Newark, DE).

\section{Study funding}

No targeted funding reported.

\section{Disclosure}

The authors report no relevant disclosures. Go to Neurology. org/ $\mathrm{N}$ for full disclosures.

\section{Publication history}

Received by Neurology April 17, 2020. Accepted in final form May 5, 2020.

\begin{tabular}{|c|c|c|}
\hline Name & Location & Contribution \\
\hline $\begin{array}{l}\text { Michael A. } \\
\text { Rubin, MD, } \\
\text { MA }\end{array}$ & $\begin{array}{l}\text { UT Southwestern, } \\
\text { Dallas, TX }\end{array}$ & $\begin{array}{l}\text { Conceptualization, primary } \\
\text { writer, incorporated feedback } \\
\text { and edits }\end{array}$ \\
\hline $\begin{array}{l}\text { Richard J. } \\
\text { Bonnie, LLB }\end{array}$ & $\begin{array}{l}\text { University of Virginia, } \\
\text { Charlottesville }\end{array}$ & $\begin{array}{l}\text { Conceptualization, significant } \\
\text { edits }\end{array}$ \\
\hline $\begin{array}{l}\text { Leon } \\
\text { Epstein, MD }\end{array}$ & $\begin{array}{l}\text { Northwestern } \\
\text { University, Chicago, IL }\end{array}$ & Conceptualization and edits \\
\hline $\begin{array}{l}\text { Claude } \\
\text { Hemphill, } \\
\text { MD, MAS }\end{array}$ & $\begin{array}{l}\text { University of } \\
\text { California, San } \\
\text { Francisco }\end{array}$ & $\begin{array}{l}\text { Conceptualization, significant } \\
\text { edits }\end{array}$ \\
\hline $\begin{array}{l}\text { Matthew } \\
\text { Kirschen, } \\
\text { MD, PhD }\end{array}$ & $\begin{array}{l}\text { University of } \\
\text { Pennsylvania, } \\
\text { Philadelphia }\end{array}$ & Writer and edits \\
\hline $\begin{array}{l}\text { Ariane } \\
\text { Lewis, MD }\end{array}$ & $\begin{array}{l}\text { New York University, } \\
\text { New York }\end{array}$ & Major conceptualization, edits \\
\hline $\begin{array}{l}\text { Jose I. } \\
\text { Suarez, MD }\end{array}$ & $\begin{array}{l}\text { Johns Hopkins } \\
\text { University, Baltimore, } \\
\text { Maryland }\end{array}$ & Conceptualization and edits \\
\hline
\end{tabular}

\section{References}

1. AMA Council on Ethical and Judicial Affairs. AMA Code of Medical Ethics' opinion on allocating medical resources.Virtual Mentor 2011;13:228-229.

2. Kinlaw K, Levine R. Ethical guidelines in pandemic influenza: Ethics Subcommittee of the Advisory Committee to the Director, Center for Disease Control and Prevention. 2017. Available at: https://www.cdc.gov/os/integrity/phethics/docs/White_Paper_ Final_for_Website_2012_4_6_12_final_for_web_508_compliant.pdf. Accessed April 27,2020 .

3. Berlinger N, Wynia M, Powell T, et al. Ethical framework for health care institutions responding to novel coronavirus SARS-CoV-2 (COVID-19): The Hastings Center. 2020. Available at: thehastingscenter.org/ethicalframeworkcovid19/. Accessed April 27, 2020.

4. Yancy CW. COVID-19 and African Americans. JAMA Epub 2020 Apr 15.

5. Hatcher-Martin JM, Adams JL, Anderson ER, et al. Telemedicine in neurology: Telemedicine Work Group of the American Academy of Neurology update. Neurology 2020;94:30-38.

6. Gallagher TH, Schleyer AM. "We signed up for this!" Student and trainee responses to the COVID-19 pandemic. N Engl J Med Epub 2020 Apr 8.

7. Association of American Medical Colleges. Compact between resident physicians and their teachers. Available at: aamc.org/residentcompact. Accessed April 27, 2020.

8. Emanuel EJ, Persad G, Upshur R, et al. Fair allocation of scare medical resources in the time of COVID-19. N Engl J Med Epub 2020 Mar 23.

9. Breslow J. NYC could need up to 45,000 additional medical workers this month, mayor says. National Public Radio. 2020. Available at: npr.org/sections/coronaviruslive-updates/2020/04/09/830973097/nyc-could-need-up-to-45-000-additionalmedical-workers-this-month-mayor-says. Accessed April 27, 2020.

10. Rubin MA, Troug RD. What to do when there aren't enough beds in the PICU.AMA J Ethics 2017;19:157-163.

11. Troug RD, Mitchell C, Daley GQ. The toughest triage: allocating ventilators in a pandemic. N Engl J Med Epub 2020 Mar 23.

12. Biddison ELD, Faden R, Gwon H, et al. Too many patients: a framework to guide statewide allocation of scarce mechanical ventilation during disasters. Chest 2019;155: 848-854.

13. Bulletin: Civil Rights, HIPPA, and the Coronavirus Disease 2019 (COVID 19). 2020. Available at: hhs.gov/sites/default/files/ocr-bulletin-3-28-20.pdf. Accessed April 27, 2020. 


\section{Neurology}

\section{AAN position statement:: The COVID-19 pandemic and the ethical duties of the neurologist}

Michael A. Rubin, Richard J. Bonnie, Leon Epstein, et al.

Neurology 2020;95;167-172 Published Online before print May 15, 2020

DOI 10.1212/WNL.0000000000009744

\section{This information is current as of May 15, 2020}

\section{Updated Information \& Services}

References

Citations

Subspecialty Collections

Permissions \& Licensing

Reprints including high resolution figures, can be found at: http://n.neurology.org/content/95/4/167.full

This article cites 4 articles, 1 of which you can access for free at: http://n.neurology.org/content/95/4/167.full\#ref-list-1

This article has been cited by 1 HighWire-hosted articles: http://n.neurology.org/content/95/4/167.full\#\#otherarticles

This article, along with others on similar topics, appears in the following collection(s):

All Ethics in Neurology/Legal issues

http://n.neurology.org/cgi/collection/all_ethics_in_neurology_legal_iss ues

Health policy

http://n.neurology.org/cgi/collection/health_policy

Professional conduct and ethics

http://n.neurology.org/cgi/collection/professional_conduct_and_ethics

Public health

http://n.neurology.org/cgi/collection/public_health

Information about reproducing this article in parts (figures,tables) or in its entirety can be found online at:

http://www.neurology.org/about/about_the_journal\#permissions

Information about ordering reprints can be found online:

http://n.neurology.org/subscribers/advertise

Neurology ${ }^{\circledR}$ is the official journal of the American Academy of Neurology. Published continuously since 1951, it is now a weekly with 48 issues per year. Copyright @ 2020 American Academy of Neurology. All rights reserved. Print ISSN: 0028-3878. Online ISSN: 1526-632X.

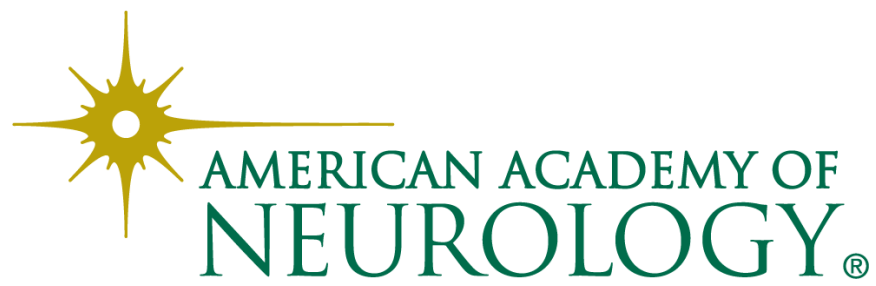

